CLINICAL STUDY

\title{
The association between serum parathyroid hormone and bone mineral density, and the impact of smoking: the Tromso Study
}

\author{
Monica Sneve $^{1}$, Nina Emaus ${ }^{2}$, Ragnar Martin Joakimsen ${ }^{3,4}$ and Rolf Jorde ${ }^{1,4}$ \\ ${ }^{1}$ Department of Internal Medicine, University Hospital of North Norway, 9038 Tromsø, Norway, ${ }^{2}$ Institute of Community Medicine, University of \\ Tromsø, 9037 Tromsø, Norway, ${ }^{3}$ Department of Nephrology, University Hospital of North Norway, 9038 Tromsø, Norway and ${ }^{4}$ Institute of Clinical \\ Medicine, University of Tromsø, 9037 Tromsø, Norway \\ (Correspondence should be addressed to M Sneve who is now at Medical Department B, Post box 101, University Hospital of North Norway, 9038 Tromsø, \\ Norway; Email: monica.sneve@unn.no)
}

\begin{abstract}
Objective: To explore the relation between serum parathyroid hormone (PTH) and bone mineral density (BMD), adjusted for lifestyle factors including smoking.

Design: Cross-sectional study.

Methods: The Tromsø Study is a population-based study performed for the fifth time in 2001. Serum PTH was measured and the subjects filled in a questionnaire covering lifestyle factors. BMD at the hip, distal and ultradistal forearm was measured.

Results: Complete datasets were available in 1442 men and 1368 women. Age, body mass index and serum PTH were strong predictors of BMD level at the hip in both genders. No significant relation was seen between serum PTH and BMD at the distal or ultradistal forearm. When smokers and nonsmokers were analysed separately, the relation between PTH and BMD at the hip was significant in current non-smokers only. In males, current non-smokers had significantly higher BMD at all three measurement sites compared with current smokers. Male former smokers had values in between current and never smokers. There was a significant and negative relation between number of years smoked and BMD at the hip. In male former smokers, there was an increase in BMD with increasing years since smoking cessation.

Conclusion: Serum PTH is negatively associated with BMD at the hip, and the relation seems to be masked, or diminished, by smoking. Smoking reduces BMD at the hip, distal and ultradistal forearm in males, and the effect appears to be mainly time and not dose dependent.
\end{abstract}

European Journal of Endocrinology 158 401-409

\section{Introduction}

Bone mass is affected by several factors, with gender, age, physical activity, genes and intake of calcium and vitamin $\mathrm{D}$ among the most important $(1,2)$.

Parathyroid hormone (PTH) is a main regulator of the calcium homeostasis (3). Secretion of PTH is stimulated by hypocalcaemia and suppressed by hypercalcaemia. As PTH rises in response to hypocalcaemia, it will tend to restore eucalcaemia by causing bone resorption, reduced renal calcium excretion, and, by its stimulation of renal conversion of 25-hydroxyvitamin D to 1,25-dihydroxyvitamin D, increased intestinal calcium absorption $(4,5)$. Even minor changes in the extracellular ionized calcium concentration cause large changes in PTH release, and the serum level of PTH may be considered a marker of the body's calcium status. Considering the importance of calcium metabolism for bone health, one would therefore expect a negative association between serum PTH and bone mineral density (BMD). In accordance with this, a reduced BMD has been demonstrated both in subjects with primary $(6,7)$ and secondary $(8,9)$ hyperparathyroidism.

However, in epidemiological studies, the association between PTH and BMD is more uncertain. In the Rancho Bernardo Study, there was a significant negative association between serum PTH and BMD at the hip in older men and women $(10,11)$, which was not found by Garnero et al. in a study on postmenopausal women (12). In the MINOS study, the relation between PTH and BMD was significant in older men only (13). In several of these studies, adjustment for smoking status, which may affect both serum PTH and BMD $(14,15)$, was not performed $(12,13)$. This could be of considerable importance as even a modest number of cigarettes smoked per day cause a significant reduction of the serum PTH level (16), and smoking is strongly associated with osteoporosis $(14,17,18)$. The effect of smoking on bone appears to be more pronounced in men and in the elderly $(14,19)$. However, the effect of number of cigarettes smoked per day and the effect of smoking cessation are uncertain (20-22). 
In the fifth Tromsø Study, BMD was measured at the hip and the forearm, smoking status was recorded, and serum PTH measured in 2810 subjects. A large database was therefore available for evaluating the relation between BMD, serum PTH and smoking.

\section{Subjects and methods}

\section{Subjects}

The Tromsø Study is a population-based multipurpose study focusing on lifestyle-related diseases, and was first performed in 1974 (23). In the fifth Tromsø Study, performed in 2001, 10353 subjects were invited, of whom 8130 accepted to participate. Of the attendants, 6969 subjects were invited for a comprehensive examination which included BMD measurements, and 5939 subjects (2447 men and 3492 women) accepted the invitation. BMD at the hip was measured in 5300 subjects, of which 695 scans had to be excluded because of prostheses or nails, or scans where the region of interest was out of scan. Furthermore, subjects with ineligible forearm scans, those missing PTH measurements, users of hormone replacement therapy, contraceptive pills or medication for osteoporosis, cigar, cigarillo or pipe smokers, those with serum calcium $>2.55 \mathrm{mmol} / \mathrm{l}$, and those with incomplete questionnaires were excluded, leaving 2810 subjects (1442 males and 1368 females) for the final analyses. Figure 1 displays a flow chart of the study population.

\section{Questionnaires}

All subjects filled in two self-administered questionnaires, one on entering the study and the other which they filled in at home and returned by either mail or entering the comprehensive examination. The questionnaires covered general health, smoking status including number of cigarettes smoked per day, physical activity in spare time, use of vitamin D and calcium supplements, use of hormone replacement therapy and osteoporosis medications, and alcohol and coffee consumption.

The subjects were classified as current smokers or current non-smokers of cigarettes. The current nonsmokers were further subclassified into former and never smokers. Pack years were calculated by multiplying the number of cigarettes smoked per day with years smoked, divided by 20 . Those smoking cigars, cigarillos or pipe only, or in addition to cigarettes, were excluded as there were no questions regarding number of cigars, cigarillos or pipes smoked per day. Distinction between ordinary cigarettes and hand-rolled cigarettes was not made.

A physical activity score was calculated as the sum of hours of light and heavy physical activity in spare time per week, with heavy physical activity given double weight. Coffee consumption was calculated as the sum of cups of all types of coffee (brewed, filtered or other type) drunk per day. Alcohol consumption was calculated as the number of glasses of alcohol (adding glasses of wine, beer and spirits) consumed in 2 weeks, assuming equal units of alcohol in each glass.

\section{Measurements}

Height and weight were measured wearing light clothing and no shoes. Body mass index (BMI) was calculated as weight $(\mathrm{kg})$ divided by squared height $\left(\mathrm{m}^{2}\right)$.

BMD was measured at the hip by dual-energy X-ray absorptiometry (DEXA) according to the manufacturer (GE Lunar Prodigy, LUNAR Corporation, Madison, WI, USA). The mean of the right and left total hip value was used in the analyses. BMD at the distal and ultradistal forearm was measured with two single X-ray absorptiometric devices (DTX-100; Osteometer Medi-Tech Inc., Hawthorne, CA, USA). The distal forearm measurement included both the radius and the ulna from the $8 \mathrm{~mm}$ point (the point where the radius and ulna are separated by $8 \mathrm{~mm}$ ) and $24 \mathrm{~mm}$ proximally. The ultradistal forearm measurement included only the radius, from the $8 \mathrm{~mm}$ point and up to the endplate. The nondominant arm was measured, except when it was ineligible. The measurements of BMD at the forearm are previously described in detail (24). All scans were performed and reviewed by specially trained technicians.

Blood samples were drawn in the non-fasting state. Serum calcium, creatinine and PTH were measured as previously described (25). Reference ranges in our laboratory are for serum calcium, 2.20-2.60 mmol/l; for serum creatinine, $70-120 \mu \mathrm{mol} / \mathrm{l}$ for men and 55-100 $\mu \mathrm{mol} / \mathrm{l}$ for women; and for serum PTH, 1.1-6.8 pmol/l for those 50 years old and younger and 1.1-7.5 pmol/l for those older than 50 years.

\section{Statistical analyses}

Normal distribution was evaluated with visual inspection of histograms with normal curve, normality plots $(Q-Q-$ plots $)$, and determination of skewness and kurtosis. All dependent variables were considered normally distributed.

An initial regression analysis with total hip BMD as dependent variable and PTH quartiles, gender and smoking status as factors, and age, BMI, coffee and alcohol consumption, physical activity score, serum calcium and creatinine as independent variables, revealed significant interaction between smoking status and gender. Therefore, all analyses were done separately for males and females. In the gender-specific regression models, there were no interaction between alcohol consumption and smoking status. Alcohol consumption, serum calcium and creatinine were not significant predictors of BMD at any of the measurement sites, and were therefore excluded from the final regression models.

Groups were compared with Student's t-test, and for the BMD measurements also with multiple linear 


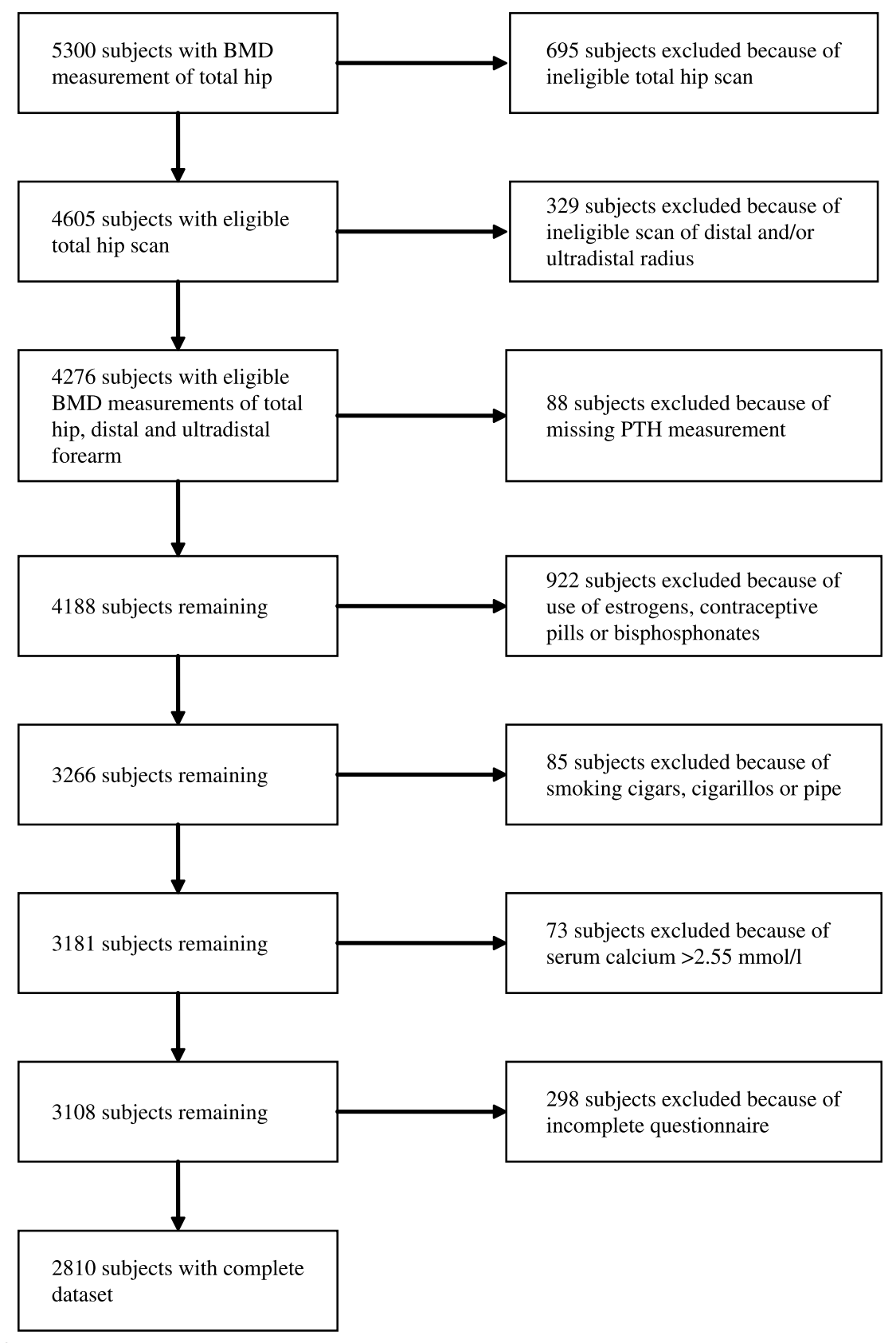

Figure 1 Flow chart of the study population.

regression with variables similar to the initial regression analysis. For evaluation of individual predictors of $\mathrm{BMD}$, a multiple linear regression model with variables similar to the initial regression analysis was used. Linear trend across PTH quartiles and groups, in relation to number of cigarettes smoked daily, number of years smoked and number of years since quitted smoking, were evaluated with multiple linear regression with covariates as in the initial regression analysis. Analysis of covariance was used to calculate adjusted means of BMD total hip by age and BMI.
Unless otherwise stated, data are expressed as mean \pm s.D. All tests were done two-sided, and $P$ value $<0.05$ was considered statistically significant. The Statistical Package for Social Sciences version 14.0 was used for all statistical analyses (SPSS Inc., Chicago, IL, USA).

\section{Ethics}

The study was approved by the Regional Ethics Committee. All participants gave written informed consent prior to the study. 
Table 1 Characteristics of the study subjects in relation to gender and smoking status.

\begin{tabular}{|c|c|c|c|c|c|c|c|c|c|c|}
\hline & \multicolumn{5}{|c|}{ Male } & \multicolumn{5}{|c|}{ Females } \\
\hline & All males & $\begin{array}{l}\text { Current } \\
\text { non-smokers }\end{array}$ & $\begin{array}{l}\text { Current } \\
\text { smokers }\end{array}$ & $\begin{array}{l}\text { Former } \\
\text { smokers }\end{array}$ & $\begin{array}{l}\text { Never } \\
\text { smokers }\end{array}$ & All females & $\begin{array}{l}\text { Current } \\
\text { non-smokers }\end{array}$ & $\begin{array}{l}\text { Current } \\
\text { smokers }\end{array}$ & $\begin{array}{l}\text { Former } \\
\text { smokers }\end{array}$ & $\begin{array}{l}\text { Never } \\
\text { smokers }\end{array}$ \\
\hline$N$ & 1442 & 1101 & 341 & 784 & 317 & 1368 & 1014 & 354 & 421 & 593 \\
\hline Age (years) & $65.5 \pm 9.5$ & $66.1 \pm 9.4^{\ddagger}$ & $63.3 \pm 9.4$ & $67.5 \pm 8.3$ & $62.9 \pm 11.1^{\pi}$ & $63.6 \pm 10.0$ & $64.5 \pm 9.8^{\ddagger}$ & $60.9 \pm 10.4^{\pi}$ & $64.2 \pm 9.2$ & $64.7 \pm 10.2$ \\
\hline BMI $\left(\mathrm{kg} / \mathrm{m}^{2}\right)$ & $26.6 \pm 3.1$ & $26.9 \pm 3.0^{\ddagger}$ & $25.7 \pm 3.1^{\pi}$ & $27.1 \pm 3.1$ & $26.6 \pm 2.8^{\S}$ & $27.0 \pm 4.4$ & $27.6 \pm 4.3^{\ddagger}$ & $25.2 \pm 4.2^{\pi}$ & $27.7 \pm 4.3$ & $27.5 \pm 4.3$ \\
\hline S-PTH (pmol/l) & $3.56 \pm 1.70$ & $3.69 \pm 1.78^{\ddagger}$ & $3.12 \pm 1.32^{\pi}$ & $3.67 \pm 1.74$ & $3.75 \pm 1.87$ & $3.40 \pm 1.53$ & $3.52 \pm 1.54^{\ddagger}$ & $3.07 \pm 1.44^{\top}$ & $3.55 \pm 1.60$ & $3.49 \pm 1.50$ \\
\hline $\begin{array}{l}\text { S-calcium } \\
(\mathrm{mmol} / \mathrm{l})\end{array}$ & $2.35 \pm 0.08$ & $2.34 \pm 0.08^{*}$ & $2.36 \pm 0.07^{\|}$ & $2.34 \pm 0.08$ & $2.35 \pm 0.08^{\S}$ & $2.37 \pm 0.08$ & $2.37 \pm 0.08$ & $2.37 \pm 0.08$ & $2.37 \pm 0.08$ & $2.37 \pm 0.08$ \\
\hline $\begin{array}{l}\text { S-creatinine } \\
(\mu \mathrm{mol} / /)\end{array}$ & $98.9 \pm 17.7$ & $100.1 \pm 18.9^{\ddagger}$ & $94.7 \pm 12.4^{\pi}$ & $100.4 \pm 20.6$ & $99.5 \pm 13.8$ & $82.9 \pm 10.3$ & $83.5 \pm 10.2^{\ddagger}$ & $81.2 \pm 10.4^{\S}$ & $83.1 \pm 10.8$ & $83.8 \pm 9.8$ \\
\hline $\begin{array}{l}\text { Physical } \\
\text { activity } \\
\text { score }\end{array}$ & $4.3 \pm 3.2$ & $4.4 \pm 3.2^{*}$ & $3.9 \pm 3.2$ & $4.2 \pm 3.2$ & $4.8 \pm 3.2^{\| 1}$ & $3.6 \pm 2.8$ & $3.6 \pm 2.7$ & $3.4 \pm 2.9$ & $3.5 \pm 2.6$ & $3.7 \pm 2.8$ \\
\hline $\begin{array}{l}\text { Coffee } \\
\text { (cups/day) }\end{array}$ & $5.1 \pm 3.1$ & $4.4 \pm 2.5^{\ddagger}$ & $7.1 \pm 3.7^{\pi}$ & $4.7 \pm 2.5$ & $3.9 \pm 2.6^{\pi}$ & $4.3 \pm 2.5$ & $3.7 \pm 2.1^{\ddagger}$ & $5.8 \pm 2.8^{\pi}$ & $4.1 \pm 2.2$ & $3.5 \pm 2.0^{\pi}$ \\
\hline $\begin{array}{l}\text { BMD total hip } \\
\left(\mathrm{g} / \mathrm{cm}^{2}\right)\end{array}$ & $1.012 \pm 0.133$ & $\begin{array}{l}1.023 \pm \\
0.131^{\ddagger, c}\end{array}$ & $\begin{array}{l}0.975 \pm \\
0.130^{\uparrow, e}\end{array}$ & $1.015 \pm 0.132$ & $\begin{array}{l}1.044 \pm \\
0.127^{\|, \mathrm{e}}\end{array}$ & $0.899 \pm 0.132$ & $0.906 \pm 0.131^{\dagger}$ & $0.881 \pm 0.133^{\|}$ & $0.906 \pm 0.126$ & $0.906 \pm 0.135$ \\
\hline $\begin{array}{l}\text { BMD distal } \\
\text { forearm } \\
\left(\mathrm{g} / \mathrm{cm}^{2}\right)\end{array}$ & $0.531 \pm 0.067$ & $\begin{array}{l}0.534 \pm \\
0.066^{\dagger, b}\end{array}$ & $0.522 \pm 0.070$ & $0.528 \pm 0.069$ & $\begin{array}{l}0.546 \pm \\
0.057^{\uparrow, d}\end{array}$ & $0.397 \pm 0.069$ & $0.395 \pm 0.068^{*}$ & $0.403 \pm 0.072$ & $0.397 \pm 0.065$ & $0.393 \pm 0.070$ \\
\hline $\begin{array}{l}\text { BMD ultradistal } \\
\text { forearm } \\
\left(\mathrm{g} / \mathrm{cm}^{2}\right)\end{array}$ & $0.436 \pm 0.068$ & $\begin{array}{l}0.439 \pm \\
0.068^{\star, a}\end{array}$ & $0.428 \pm 0.068$ & $0.434 \pm 0.069$ & $0.450 \pm 0.064^{\pi}$ & $0.302 \pm 0.064$ & $0.300 \pm 0.064$ & $0.306 \pm 0.064$ & $0.302 \pm 0.063$ & $0.299 \pm 0.065$ \\
\hline $\begin{array}{l}\text { Cigarettes per } \\
\text { day }\end{array}$ & & & $11.4 \pm 5.5^{\|}$ & $12.7 \pm 8.4$ & & & & $9.9 \pm 4.7^{\pi}$ & $8.4 \pm 5.4$ & \\
\hline Years smoked & & & $42.0 \pm 11.4^{\pi}$ & $26.7 \pm 13.8$ & & & & $35.6 \pm 11.0^{\pi}$ & $20.9 \pm 12.5$ & \\
\hline $\begin{array}{l}\text { Alcohol } \\
\text { (glasses/2 } \\
\text { weeks) }\end{array}$ & $6.4 \pm 6.5$ & $6.2 \pm 6.0$ & $7.0 \pm 7.6$ & $6.5 \pm 6.3$ & $5.4 \pm 5.3$ & $3.9 \pm 4.5$ & $3.6 \pm 4.2$ & $4.6 \pm 5.2$ & $4.1 \pm 4.7$ & $3.2 \pm 3.6$ \\
\hline
\end{tabular}

${ }^{\star} P<0.05,{ }^{\dagger} P<0.01,{ }^{\ddagger} P<0.001$ versus current smokers, ${ }^{\S} P<0.05, "{ }^{\|} P<0.01,{ }^{\mathrm{T}} P<0.001$ versus former smokers (Student's $t$-test). ${ }^{\mathrm{a}} P<0.05,{ }^{\mathrm{b}} P<0.01,{ }^{\mathrm{c}} P<0.001$ versus current $s m 0$ kers, ${ }^{\mathrm{d}} P<0.05,{ }^{\mathrm{e}} P<0.01$ versus former smokers (linear regression with age, BMI, serum PTH, coffee consumption and physical activity as covariates). 


\section{Results}

\section{Relation between serum PTH and BMD}

The characteristics of the subjects are shown in Table 1. In the multiple linear regression models, serum PTH was a significant negative predictor of BMD at the hip in both genders. No significant relation was found between serum PTH and BMD at the distal or ultradistal forearm. In addition to PTH, age and smoking were also strong negative predictors of BMD, whereas BMI and physical activity were strong positive predictors of BMD (Table 2).

When dividing the cohort according to PTH quartiles, with increasing PTH quartile, there was a gradual increase in BMI and age, and a decrease in BMD at the hip, in the multiple linear regression model. There was also, with increasing PTH quartile, a decrease in the number of smokers. The difference in BMD at the hip was 3\% between the lowest and the highest PTH quartiles. The significant linear trend for BMD at the hip across serum PTH quartiles was also seen when analysing non-smokers separately, but not when analysing smokers separately (Table 3 ).

The relation between serum PTH and BMD at the hip was also statistically significant in females $<55$ years of age $(n=169, P<0.05)$, whereas this did not reach statistical significance in males $<55$ years $(n=168$, $P=0.16$, multivariate analysis).

Supplements with calcium tablets, vitamin D or cod liver oil were taken by $12.1,26.0$ and $53.5 \%$ of the females and 1.6, 11.5 and $47.4 \%$ of the males respectively. In general, those taking supplements were older, leaner and had lower BMD at all three measurement sites, but the differences were not statistically significant in multiple linear regression analysis. Females taking calcium supplements had significantly lower serum PTH levels than those without calcium supplements $(3.0 \mathrm{pmol} / \mathrm{l}$ vs $3.4 \mathrm{pmol} / \mathrm{l}$ respectively, $P<0.001)$. Inclusion of taking supplements into the multiple linear regression analysis did not alter the relation between serum PTH and BMD.

\section{Relation between smoking status and BMD}

Using Student's t-test, current non-smokers were significantly older, had higher BMI, serum PTH and creatinine levels, and lower coffee consumption than current smokers. In males, the BMD at the hip, distal and ultradistal forearm were significantly higher in the current non-smokers compared with the smokers, even after adjusting for differences in age, BMI, serum PTH, physical activity and coffee consumption. In females, BMD at these three sites did not differ significantly between smokers and non-smokers after adjusting for the confounders. When dividing the current nonsmokers into former smokers and never smokers, male former smokers had BMD values at the three sites in between those for current smokers and never smokers (Table 1).

\section{Relation between smoking exposure and BMD}

In the multiple linear regression models with age, BMI, serum PTH, coffee consumption and physical activity as covariates, there were no statistical significant relations between numbers of cigarettes smoked daily or pack years and measurements of BMD neither in current smokers nor in former smokers. However, for BMD at the hip, in former smokers of both genders, there was a significant negative relation with numbers of years smoked, and in males a significant positive relation with number of years since smoking cessation. These relations between number of cigarettes smoked, number of years smoked, and number of years since quitting smoking and BMD at the hip, are shown in Tables 4 and 5.

The negative relation between number of years smoked and BMD was also seen in male former smokers

Table 2 Standardized regression coefficient $\beta$ and $t$ values from the linear regression models with bone mineral density (BMD) total hip, distal and ultradistal forearm as dependent variables in the 1442 males and 1368 females.

\begin{tabular}{|c|c|c|c|c|c|c|c|c|c|c|c|c|}
\hline \multirow{3}{*}{$\begin{array}{l}\text { Independent vari- } \\
\text { ables }\end{array}$} & \multicolumn{6}{|c|}{ Males } & \multicolumn{6}{|c|}{ Females } \\
\hline & \multicolumn{2}{|c|}{ BMD hip $\left(\mathrm{g} / \mathrm{cm}^{2}\right)$} & \multicolumn{2}{|c|}{$\begin{array}{l}\text { BMD distal fore- } \\
\operatorname{arm}\left(\mathrm{g} / \mathrm{cm}^{2}\right)\end{array}$} & \multicolumn{2}{|c|}{$\begin{array}{l}\text { BMD ultradistal } \\
\text { forearm }\left(\mathrm{g} / \mathrm{cm}^{2}\right)\end{array}$} & \multicolumn{2}{|c|}{ BMD hip $\left(\mathrm{g} / \mathrm{cm}^{2}\right)$} & \multicolumn{2}{|c|}{$\begin{array}{l}\text { BMD distal fore- } \\
\operatorname{arm}\left(\mathrm{g} / \mathrm{cm}^{2}\right)\end{array}$} & \multicolumn{2}{|c|}{$\begin{array}{l}\text { BMD ultradistal } \\
\text { forearm }\left(\mathrm{g} / \mathrm{cm}^{2}\right)\end{array}$} \\
\hline & $\beta$ & $t$ & $\beta$ & $t$ & $\beta$ & $t$ & $\beta$ & $t$ & $\beta$ & $t$ & $\beta$ & $t$ \\
\hline Age (years) & -0.16 & -6.48 & -0.34 & -13.44 & -0.29 & -11.43 & -0.42 & -18.24 & -0.59 & -25.97 & -0.51 & -21.49 \\
\hline BMI $\left(\mathrm{kg} / \mathrm{m}^{2}\right)$ & 0.30 & 12.26 & 0.15 & 6.06 & 0.15 & 5.79 & 0.45 & 19.48 & 0.18 & 7.97 & 0.17 & 6.98 \\
\hline PTH (pmol/l) & -0.09 & -3.50 & 0.00 & 0.14 & -0.02 & -0.71 & -0.09 & -4.02 & -0.03 & -1.42 & -0.05 & -1.90 \\
\hline $\begin{array}{l}\text { Physical activity } \\
\text { score }\end{array}$ & 0.09 & 3.68 & 0.05 & 1.83 & 0.07 & 2.70 & 0.01 & 0.55 & 0.03 & 1.13 & 0.03 & 1.43 \\
\hline Coffee (cups/day) & -0.03 & -1.25 & -0.02 & -0.65 & -0.02 & -0.78 & -0.05 & -1.98 & 0.00 & 0.15 & 0.00 & 0.11 \\
\hline $\begin{array}{l}\text { Current smoking } \\
\text { status }^{a}\end{array}$ & 0.12 & 4.35 & 0.09 & 3.14 & 0.07 & 2.59 & 0.04 & 1.40 & -0.00 & -0.08 & 0.00 & 0.29 \\
\hline$R^{2}$ & & 0.17 & & 0.15 & & 0.13 & & 0.35 & & 0.36 & & 0.29 \\
\hline
\end{tabular}

a Smoker $=1$, non-smoker $=2$. Values of $|t|>1.96,|t|>2.58$ and $|t|>3.29$ corresponds to $P<0.05, P<0.01$ and $P<0.001$ respectively. 


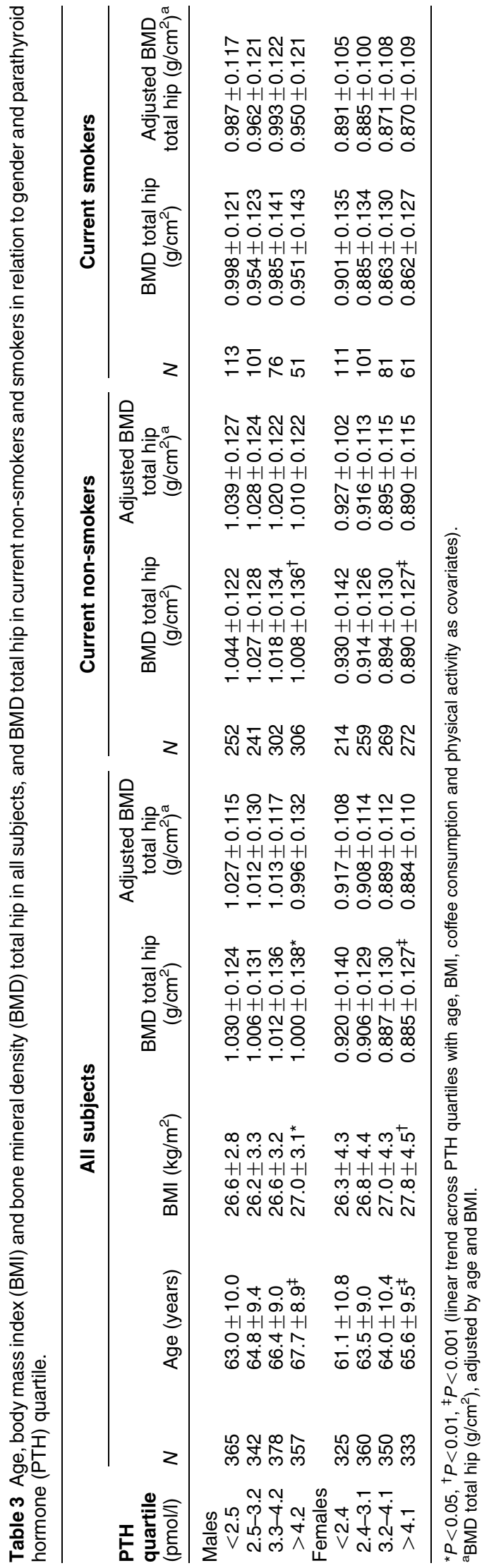

at the distal and ultradistal forearm $(P<0.05)$. In female former smokers, there was a significant positive association between the numbers of years since quitting smoking and BMD at the distal forearm $(P<0.01)$, data not shown.

\section{Discussion}

In the present study, we found PTH to be a significant negative predictor of BMD at the hip in both genders, whereas no association was found between PTH and BMD at the distal and ultradistal forearm. As expected, we also found age, BMI, physical activity and smoking to be strong predictors of BMD $(1,18)$. With increasing PTH levels, there was an increase in BMI and age, and a decrease in number of smokers, in accordance with previous reports from the fifth Tromsø Study $(16,26)$.

There are several studies on the relation between serum PTH and BMD. In most $(8,10,11,13,27)$, but not all (12), serum PTH has been negatively associated with BMD at the hip. However, the relation between serum PTH and BMD appears to be related to type of bone measured. Thus, in contrast to what appears to be the case for PTH and the predominantly cortical bone at the hip (28), there seems to be no relation between serum PTH and BMD in the vertebras (10), which are mainly composed of trabecular bone. However, in accordance with others (13), we did not find any relation between PTH and BMD at the distal forearm, which is composed of $10-20 \%$ trabecular bone, nor at the ultradistal forearm, which is composed of $50-70 \%$ trabecular bone. This implies that other factors are also of importance regarding PTH and BMD, for example, the impact of weight bearing.

In experimental studies, PTH exerts a binary action on bone as it stimulates both osteoblast and osteoclast activities (29). Intermittent injections with PTH increase osteoblast recruitment, lifespan and activity, whereas continuously elevated levels of PTH activates osteoclasts causing diminished BMD (3). PTH has emerged as an effective therapeutic agent for osteoporosis (3), and it is intriguing that the effect seems to be greater on trabecular bone than on cortical bone. Whether the effect of PTH injections in osteoporosis is a direct effect on bone, or (partially) through stimulation of 1,25 hydroxylation of vitamin D, is uncertain. In the PaTH trial, women with larger changes in 1,25dihydroxyvitamin $\mathrm{D}$ during the intervention had larger gains in BMD (30). The authors suggested that some individuals are more responsive to PTH than others, and that 1,25-dihydroxyvitamin $\mathrm{D}$ may play a role in the increased bone density after PTH injections.

Similarly, the relation between serum PTH and BMD found in the present study may not represent a causative effect of PTH, but may reflect covariation with other factors important for bone health. In particular, the intake of calcium and vitamin $\mathrm{D}$ are 
Table 4 Smoking status, age, body mass index (BMI) and bone mineral density (BMD) at the hip in relation to number of cigarettes smoked, number of years smoked and number of years since quitting smoking in males.

\begin{tabular}{|c|c|c|c|c|c|c|c|c|}
\hline & \multicolumn{4}{|c|}{ Current smokers } & \multicolumn{4}{|c|}{ Former smokers } \\
\hline & $N^{\mathrm{a}}$ & Age (years) & BMI $\left(\mathrm{kg} / \mathrm{m}^{2}\right)$ & $\begin{array}{l}\text { BMD hip } \\
\left(\mathrm{g} / \mathrm{cm}^{2}\right)\end{array}$ & $N^{\mathrm{a}}$ & Age (years) & BMI $\left(\mathrm{kg} / \mathrm{m}^{2}\right)$ & $\begin{array}{l}\text { BMD hip } \\
\left(\mathrm{g} / \mathrm{cm}^{2}\right)\end{array}$ \\
\hline \multicolumn{9}{|c|}{ Number of cigarettes smoked daily } \\
\hline $1-5$ & 42 & $64.8 \pm 10.3$ & $24.8 \pm 3.7$ & $0.964 \pm 0.164$ & 90 & $68.1 \pm 6.2$ & $26.1 \pm 3.2$ & $0.998 \pm 0.134$ \\
\hline $6-10$ & 148 & $64.9 \pm 8.3$ & $25.6 \pm 2.9$ & $0.975 \pm 0.126$ & 306 & $67.3 \pm 9.0$ & $27.0 \pm 2.8$ & $1.020 \pm 0.135$ \\
\hline $11-15$ & 94 & $62.4 \pm 8.0$ & $26.1 \pm 3.3$ & $0.981 \pm 0.125$ & 143 & $66.7 \pm 8.4$ & $27.2 \pm 3.1$ & $1.038 \pm 0.124$ \\
\hline$\geq 16$ & 51 & $58.0 \pm 11.5$ & $25.7 \pm 3.0$ & $0.976 \pm 0.131$ & 150 & $66.0 \pm 8.5$ & $27.7 \pm 3.4^{*}$ & $1.003 \pm 0.131$ \\
\hline \multicolumn{9}{|c|}{ Number of years smoked } \\
\hline $1-10$ & 6 & $58.7 \pm 15.1$ & $27.0 \pm 3.9$ & $1.167 \pm 0.095$ & 107 & $63.0 \pm 9.8$ & $26.7 \pm 2.8$ & $1.050 \pm 0.118$ \\
\hline $11-20$ & 17 & $49.0 \pm 14.8$ & $25.9 \pm 3.4$ & $1.006 \pm 0.084$ & 181 & $65.3 \pm 8.9$ & $27.0 \pm 3.1$ & $1.034 \pm 0.136$ \\
\hline $21-30$ & 23 & $54.8 \pm 11.5$ & $26.2 \pm 2.6$ & $0.993 \pm 0.120$ & 182 & $67.4 \pm 7.7$ & $27.3 \pm 3.1$ & $1.025 \pm 0.116$ \\
\hline $31-40$ & 91 & $58.9 \pm 6.3$ & $26.8 \pm 2.9$ & $1.009 \pm 0.134$ & 152 & $68.5 \pm 7.3$ & $27.7 \pm 3.1$ & $0.998 \pm 0.129$ \\
\hline$\geq 41$ & 200 & $67.7 \pm 5.0$ & $25.3 \pm 3.2$ & $0.950 \pm 0.126$ & 122 & $72.2 \pm 5.2^{*}$ & $26.4 \pm 3.3^{*}$ & $0.965 \pm 0.146^{*}$ \\
\hline \multicolumn{9}{|c|}{ Number of years since quitting smoking } \\
\hline $0-5$ & & & & & 114 & $63.9 \pm 10.9$ & $27.3 \pm 3.6$ & $0.995 \pm 0.131$ \\
\hline $6-10$ & & & & & 101 & $65.4 \pm 8.9$ & $27.3 \pm 3.2$ & $1.005 \pm 0.132$ \\
\hline $11-20$ & & & & & 154 & $67.6 \pm 7.9$ & $27.5 \pm 2.9$ & $1.015 \pm 0.125$ \\
\hline$\geq 21$ & & & & & 391 & $68.9 \pm 7.1^{*}$ & $26.8 \pm 3.0$ & $1.022 \pm 0.133^{*}$ \\
\hline
\end{tabular}

${ }^{\star} P<0.001$ (linear trend across groups with age, BMI, coffee consumption and physical activity as covariates).

${ }^{a}$ Not all subjects answered all questions.

important determinants of both the serum PTH level (31) and bone density $(1,2)$. Furthermore, low serum levels of vitamin D are associated with high serum levels of PTH, and both are associated with reduced BMD (32).

Unfortunately, it was not possible to calculate the intakes of calcium and vitamin D in the present study, but the intakes of supplements were recorded. Somewhat surprisingly, those taking calcium and vitamin D supplements (including cod liver oil) had slightly lower BMD than those not taking supplements, and inclusion of taking supplements in the analyses had no effect on the relation between PTH and BMD. As the number of subjects taking supplements was limited, and their reason for taking the supplements unknown, this observation should be interpreted with caution. However, it may indicate that the relation between PTH and BMD is not only a phenomenon parallel to a low calcium and/or vitamin D intake.

The serum PTH levels increase with age and BMI, and decrease with smoking. As age, BMI and smoking all are related to BMD, adjustment for these variables is mandatory when analysing the relation between PTH and BMD. Regarding smoking, we have previously shown that even moderate smoking (one to five

Table 5 Smoking status, age, body mass index (BMI) and bone mineral density (BMD) at the hip in relation to number of cigarettes smoked, number of years smoked and number of years since quitting smoking in the females.

\begin{tabular}{|c|c|c|c|c|c|c|c|c|}
\hline & \multicolumn{4}{|c|}{ Current smokers } & \multicolumn{4}{|c|}{ Former smokers } \\
\hline & $N^{\mathrm{a}}$ & Age (years) & BMI $\left(\mathrm{kg} / \mathrm{m}^{2}\right)$ & $\begin{array}{l}\text { BMD hip } \\
\left(\mathrm{g} / \mathrm{cm}^{2}\right)\end{array}$ & $N^{\mathrm{a}}$ & Age (years) & BMI $\left(\mathrm{kg} / \mathrm{m}^{2}\right)$ & $\begin{array}{l}\text { BMD hip } \\
\left(\mathrm{g} / \mathrm{cm}^{2}\right)\end{array}$ \\
\hline \multicolumn{9}{|c|}{ Number of cigarettes smoked daily } \\
\hline $1-5$ & 50 & $61.8 \pm 12.1$ & $25.3 \pm 3.5$ & $0.923 \pm 0.135$ & 135 & $66.7 \pm 8.1$ & $26.9 \pm 3.9$ & $0.872 \pm 0.122$ \\
\hline $6-10$ & 196 & $62.1 \pm 10.5$ & $25.0 \pm 4.4$ & $0.869 \pm 0.137$ & 179 & $62.4 \pm 9.7$ & $28.1 \pm 4.5$ & $0.928 \pm 0.119$ \\
\hline $11-15$ & 69 & $57.3 \pm 9.3$ & $25.4 \pm 4.1$ & $0.891 \pm 0.117$ & 40 & $62.4 \pm 8.6$ & $28.3 \pm 4.2$ & $0.922 \pm 0.147$ \\
\hline$\geq 16$ & 30 & $58.6 \pm 8.0$ & $25.3 \pm 3.8$ & $0.883 \pm 0.118$ & 27 & $61.0 \pm 10.7$ & $27.4 \pm 4.3$ & $0.911 \pm 0.105$ \\
\hline \multicolumn{9}{|c|}{ Number of years smoked } \\
\hline $1-10$ & 8 & $56.9 \pm 9.8$ & $29.9 \pm 7.5$ & $0.938 \pm 0.250$ & 99 & $61.7 \pm 10.3$ & $26.7 \pm 4.0$ & $0.916 \pm 0.122$ \\
\hline $11-20$ & 37 & $48.7 \pm 12.5$ & $24.6 \pm 4.0$ & $0.947 \pm 0.122$ & 113 & $62.3 \pm 9.3$ & $28.3 \pm 4.8$ & $0.933 \pm 0.123$ \\
\hline $21-30$ & 68 & $54.9 \pm 10.6$ & $24.9 \pm 3.3$ & $0.924 \pm 0.122$ & 98 & $64.7 \pm 8.5$ & $28.2 \pm 4.0$ & $0.903 \pm 0.124$ \\
\hline $31-40$ & 114 & $61.7 \pm 6.8$ & $25.6 \pm 4.1$ & $0.869 \pm 0.118$ & 49 & $67.0 \pm 7.2$ & $27.9 \pm 4.6$ & $0.880 \pm 0.109$ \\
\hline$\geq 41$ & 112 & $67.5 \pm 6.1$ & $24.7 \pm 4.4$ & $0.845 \pm 0.137$ & 27 & $71.0 \pm 5.9^{\dagger}$ & $27.5 \pm 4.0$ & $0.819 \pm 0.115^{*}$ \\
\hline \multicolumn{9}{|c|}{ Number of years since quitting smoking } \\
\hline $0-5$ & & & & & 75 & $62.4 \pm 9.7$ & $27.0 \pm 4.1$ & $0.894 \pm 0.127$ \\
\hline $6-10$ & & & & & 56 & $61.1 \pm 9.4$ & $28.8 \pm 4.4$ & $0.919 \pm 0.130$ \\
\hline $11-20$ & & & & & 94 & $64.7 \pm 10.1$ & $28.2 \pm 4.9$ & $0.908 \pm 0.125$ \\
\hline$\geq 21$ & & & & & 172 & $65.7 \pm 7.7^{\ddagger}$ & $27.4 \pm 4.0$ & $0.908 \pm 0.125$ \\
\hline
\end{tabular}

${ }^{\star} P<0.05,{ }^{\dagger} P<0.001,{ }^{\ddagger} P<0.01$ (linear trend across groups with age, BMI, coffee consumption and physical activity as covariates).

${ }^{\mathrm{a}}$ Not all subjects answered all questions. 
cigarettes per day) reduces the serum PTH level by $\sim 15 \%$, that there appears to be no dose-response relationship for the PTH reduction, and that within a year after smoking cessation PTH levels are restored to non-smoking levels (16). It is therefore not surprising that smoking, which is well known to reduce BMD (14, 17), may blunt or mask the apparently harmful effect of PTH on bone, as was seen in our study.

Regarding smoking and BMD, we found in smoking males significantly lower BMD at the hip and distal and ultradistal forearm compared with non-smokers, with the difference most clearly seen at the hip. The more harmful effect of smoking on trabecular bone and the gender difference is in accordance with a large metaanalysis including more than 40000 subjects from 86 studies (14). The cause of this gender difference is uncertain. However, in women smoking has an antiestrogenic effect (33), whereas in males several studies have found increased levels of free testosterone in smokers $(20,33)$. Therefore, smoking-induced changes in gonadal hormones appear as an unlikely explanation for the gender difference found in our study.

We were not able to demonstrate any significant relation between BMD at any site and number of cigarettes smoked per day or pack years, which can be attributable to information bias. However, there was a negative relation between BMD and number of years smoked, and a positive relation with years since smoking cessation. Our results indicate that the effect of smoking on bone is mainly time and not dose dependent. In line with this, former smokers had BMD values in between those of current and never smokers. The clinical implication of our study is that even moderate smoking has a harmful effect on bone, and to avoid it completely, smoking has to be stopped. Furthermore, the smokingrelated bone loss is, at least partly, reversible. However, negative effects on bone by smoking-induced early menopause and vascular changes would not be reversible.

There are several mechanisms by which smoking could induce bone loss. Smoking is associated with lower body mass, earlier menopause and possibly a damage of the blood supply to the bone (14). Smoking is also associated with a more unhealthy and sedentary lifestyle that could have an adverse effect on bone (14). Another possible mechanism is that smoking has an inhibitory effect on bone formation $(15,34)$. On the other hand, the PTH reduction associated with smoking could have a positive effect since PTH, as shown in the present study, is associated with reduced BMD. However, the PTH reduction would also lead to an increased renal calcium loss and a reduced 1,25hydroxylation of vitamin D. Smoking also reduces the serum levels of 25-hydroxyvitamin D (15) and 1,25dihydroxyvitamin $\mathrm{D}(15,34)$, which in addition to the depression of the PTH levels could explain the lack of linear trend for BMD across PTH quartiles in the smokers in our study.
Our study has several limitations. We used DEXA measurements at the hip and single X-ray absorptiometric measurements at the forearm, both of which only provide a two-dimensional measure, and not a volumetric BMD or size of the trabecular and cortical bone compartments, which could have given additional information. Furthermore, it was not possible to calculate the calcium and vitamin D intake, and the serum levels of vitamin D were not measured, nor were the effects of sex steroids assessed. The study was crosssectional, which implies that causal relations cannot be drawn, and the age distribution made results in those younger than 55 years uncertain. Blood samples were drawn in the non-fasting state, and the PTH levels may have been influenced by calcium intake. The lack of significant relation between BMD and number of cigarettes smoked daily or pack years can perhaps be explained by information bias. The estimation of the number of cigarettes smoked daily over several years probably contains some inaccuracy, and smokers tend to underestimate the number of cigarettes smoked. Another limitation is the probability of selection bias as we ended up with $\sim 40 \%$ of the invited subjects. However, as this is not a prevalence study, selection bias seems unlikely and the relation between PTH and BMD would probably not be different among those not included in the study.

However, the study also has considerable strength. It is, to our knowledge, the largest population-based study so far published on serum PTH and BMD, and a number of possible confounders were included in the analyses and strict inclusion criteria were used.

In conclusion, we have found serum PTH to be negatively associated with BMD at the hip, and this relation seems to be masked, or diminished, by smoking. Smoking reduces BMD at the hip and distal and ultradistal forearm in males, and this effect appears to be mainly time and not dose dependent. The effect of smoking diminishes after smoking cessation.

\section{Acknowledgements}

The present study was supported by a grant from The Northern Norway Regional Health Authority. We are grateful to the Tromsø Study for providing us access to the data material.

\section{References}

1 Seeman E. Pathogenesis of bone fragility in women and men. Lancet $20023591841-1850$.

2 Dennison E, Mohamed MA \& Cooper C. Epidemiology of osteoporosis. Rheumatic Diseases Clinics of North America 2006 32 617-629.

3 Hamann KL \& Lane NE. Parathyroid hormone update. Rheumatic Diseases Clinics of North America 200632 703-719. 
4 Brown EM \& Chen CJ. Calcium, magnesium and the control of PTH secretion. Bone and Mineral $19895249-257$.

5 Murray TM, Rao LG, Divieti P \& Bringhurst FR. Parathyroid hormone secretion and action: evidence for discrete receptors for the carboxyl-terminal region and related biological actions of carboxyl- terminal ligands. Endocrine Reviews 200526 78-113.

6 Jorde R \& Sundsfjord J. Bone mineral density and blood pressure in patients with asymptomatic hyperparathyroidism. The Troms Study. Journal of Internal Medicine 2000247 325-330.

7 Hagstrom E, Lundgren E, Mallmin H, Rastad J \& Hellman P. Positive effect of parathyroidectomy on bone mineral density in mild asymptomatic primary hyperparathyroidism. Journal of Internal Medicine 2006259 191-198.

8 Sahota O, Mundey MK, San P, Godber IM, Lawson N \& Hosking DJ. The relationship between vitamin $\mathrm{D}$ and parathyroid hormone: calcium homeostasis, bone turnover, and bone mineral density in postmenopausal women with established osteoporosis. Bone 2004 35 312-319.

9 Hudson JQ. Secondary hyperparathyroidism in chronic kidney disease: focus on clinical consequences and vitamin D therapies. Annals of Pharmacotherapy $2006401584-1593$.

10 Saquib N, von Mühlen D, Garland C \& Barrett-Connor E. Serum 25-hydroxyvitamin D, parathyroid hormone, and bone mineral density in men: the Rancho Bernardo study. Osteoporosis International $2006 \mathbf{1 7} 1734-1741$.

11 von Mühlen D, Greendale G, Garland C, Wan L \& BarrettConnor E. Vitamin D, parathyroid hormone levels and bone mineral density in community-dwelling older women: the Rancho Bernardo Study. Osteoporosis International 200516 1721-1726.

12 Garnero P, Munoz F, Sornay-Rendu E \& Delmas PD. Associations of vitamin D status with bone mineral density, bone turnover, bone loss and fracture risk in healthy postmenopausal women. The OFELY study. Bone $2007 \mathbf{4 0} 716-722$.

13 Szulc P, Munoz F, Marchand F, Chapuy MC \& Delmas PD. Role of vitamin $\mathrm{D}$ and parathyroid hormone in the regulation of bone turnover and bone mass in men: the MINOS Study. Calcified Tissue International 200373 520-530.

14 Ward K \& Klesges R. A meta-analysis of the effects of cigarette smoking on bone mineral density. Calcified Tissue International 200168 259-270.

15 Brot C, Jorgensen NR \& Sorensen OH. The influence of smoking on vitamin D status and calcium metabolism. European Journal of Clinical Nutrition 199953 920-926.

16 Jorde R, Saleh F, Figenschau Y, Kamycheva E, Haug E \& Sundsfjord J. Serum parathyroid hormone (PTH) levels in smokers and non-smokers. The fifth Tromsø study. European Journal of Endocrinology 2005152 39-45.

17 Law MR \& Hackshaw AK. A meta-analysis of cigarette smoking, bone mineral density and risk of hip fracture: recognition of a major effect. BMJ $1997315841-846$.

18 Lane NE. Epidemiology, etiology, and diagnosis of osteoporosis. American Journal of Obstetrics and Gynecology 2006194 (Supp 1) S3-S11.

19 Hannan MT, Felson DT, Dawson-Hughes B, Tucker KL, Cupples AL, Wilson PWF \& Kiel DP. Risk factors for longitudinal bone loss in elderly men and women: the Framingham Osteoporosis Study. Journal of Bone and Mineral Research 2000 $15710-720$
20 Lorentzon M, Mellstrom D, Haug E \& Ohlsson C. Smoking is associated with lower bone mineral density and reduced cortical thickness in young men. Journal of Clinical Endocrinology and Metabolism 200792 497-503.

21 Gerdhem P \& Obrant KJ. Effects of cigarette-smoking on bone mass as assessed by dual-energy $\mathrm{x}$-ray absorptiometry and ultrasound. Osteoporosis International 200213 932-936.

22 Szulc P, Garnero P, Claustrat B, Marchand F, Duboeuf F \& Delmas PD. Increased bone resorption in moderate smokers with low body weight: the Minos Study. Journal of Clinical Endocrinology and Metabolism $2002 \mathbf{8 7} 666-674$.

23 Thelle DS, Førde OH, Try K \& Lehmann EH. The Tromsø heart study. Methods and main results of the cross-sectional study. Acta Medica Scandinavica 1976200 107-118.

24 Emaus N, Berntsen GKR, Joakimsen R \& Fønnebø V. Longitudinal changes in forearm bone mineral density in women and men aged 45-84 years: The Tromsø Study, a Population-based Study. American Journal of Epidemiology 20065 441-449.

25 Jorde R, Bonaa KH \& Sundsfjord J. Primary hyperparathyroidism detected in a health screening. the Tromsø study. Journal of Clinical Epidemiology 200053 1164-1169.

26 Kamycheva E, Sundsfjord J \& Jorde R. Serum parathyroid hormone level is associated with body mass index. The 5th Tromsø study. European Journal of Endocrinology 2004151 167-172.

27 Pluijm SMF, Visser M, Smit JH, Popp-Snijders C, Roos JC \& Lips P. Determinants of bone mineral density in older men and women: body composition as mediator. Journal of Bone and Mineral Research $2001162142-2151$.

28 Duan Y, De Luca V \& Seeman E. Parathyroid hormone deficiency and excess: similar effects on trabecular bone but differing effects on cortical bone. Journal of Clinical Endocrinology and Metabolism $199984718-722$

29 Manolagas SC. Birth and death of bone cells: basic regulatory mechanisms and implications for the pathogenesis and treatment of osteoporosis. Endocrine Reviews 200021 115-137.

30 Sellmeyer D, Black D, Palermo L, Greenspan S, Ensrud K, Bilezikian J \& Rosen C. Heterogeneity in skeletal response to fulllength parathyroid hormone in the treatment of osteoporosis. Osteoporosis International $2007 \mathbf{1 8} 973-979$.

31 Saleh F, Jorde R \& Sundsfjord J. Effect of calcium supplementation on blood pressure in patients with secondary hyperparathyroidism. Journal of Endocrinological Investigation 200326 35-41.

32 Lips P. Vitamin D deficiency and secondary hyperparathyroidism in the elderly: consequences for bone loss and fractures and therapeutic implications. Endocrine Reviews 200122 477-501.

33 Kapoor D \& Jones TH. Smoking and hormones in health and endocrine disorders. European Journal of Endocrinology 2005152 491-499.

34 Need AG, Kemp A, Giles N, Morris HA, Horowitz M \& Nordin BEC. Relationships between intestinal calcium absorption, serum vitamin D metabolites and smoking in postmenopausal women. Osteoporosis International 200213 83-88.

Received 13 November 2007

Accepted 29 November 2007 